\title{
CORRELATION OF CLINICAL INSTRUCTORS' CHARACTERISTICS TO STUDENTS' CLINICAL SKILLS SCORE IN A MIDWIFERY SCHOOL
}

\author{
Ika Friscila ${ }^{1 *}$, Achadiyani ${ }^{2}$, Endang Sutedja ${ }^{2}$ \\ ${ }^{1}$ Fakultas Kedokteran, Universitas Padjadjaran, Bandung - INDONESIA \\ ${ }^{2}$ Bagian Pendidikan Kedokteran, Fakultas Kedokteran, Universitas Padjadjaran, Bandung - INDONESIA
}

Submitted: 02 July 2019; Final Revision from Author: 31 May 2020; Accepted: 23 June 2020

\begin{abstract}
Background: The role of the clinical instructor is very important in clinical learning process that preparing students to become health workers who are competent in the practical environment. Effective clinical instructor is instructor who has profesional competence, interpersonal relationships, personality characteristics, and teaching skills in the process of providing guidance. The aim of the study was to analyze the relationship between clinical instructor characteristics and the score of pregnancy care clinical skills and analyze the most influenced characteristics of clinical instructor in the score of pregnancy care clinical skills in students of the Akademi Kebidanan Sari Mulia in Banjarmasin City.

Methods: This study used a cross-sectional design with 11 clinical instructors and 25 Sari Mulia Midwifery Academy students using total sampling. This study used a Nursing Effectiveness Clinical Teacher Inventory questionnaire (NCTEI) questionnaire as instrument.

Results: There is a relationship between clinical instructor characteristics and the score of pregnancy care clinical skills in students, namely interpersonal relationships $(p=0.043)$ and personality characteristics $(p=0.024)$. The dominant factor associated was personality characteristics ( $P O R=4.4 ; I K$ 95\%: 1.02-19.08) with a value of $p=0.048$.

Conclusion: From this study, it can be concluded that the interpersonal relationships and personality characteristics can enhance the role of clinical instructor in the clinical learning process and personality characteristics represent the clinical instructor characteristics that are most in line with the score of pregnancy care clinical skills.
\end{abstract}

Keywords: clinical instructor, interpersonal relationships, personality, professional competence, score of clinical skills, teaching ability

\section{ABSTRAK}

Latar belakang: Peran pembimbing klinik sangat diperlukan dalam proses pembelajaran klinik yaitu mempersiapkan mahasiswa untuk menjadi tenaga kesehatan yang kompeten di lingkungan praktik. Pembimbing klinik yang efektif adalah seseorang yang memiliki kompetensi profesional, kemampuan hubungan interpersonal yang baik, karakteristik kepribadian dan kemampuan mengajar dalam proses memberikan bimbingan. Tujuan penelitian untuk menganalisis hubungan karakteristik pembimbing klinik dan nilai keterampilan klinik asuhan kehamilan dan menganalisis karakteristik pembimbing klinik yang paling berperan terhadap nilai keterampilan klinik asuhan kehamilan pada mahasiswa Akademi Kebidanan Sari Mulia Kota Banjarmasin.

*corresponding author, contact: ika.friscila.925@gmail.com 
Metode: Penelitian ini menggunakan desain cross sectional dengan sampel sebanyak 11 pembimbing klinik di Puskesmas dan 25 mahasiswa semester III Akademi Kebidanan Sari Mulia Kota Banjarmasin yang diambil secara total sampling. Pengambilan data menggunakan kuesioner Nursing Clinical Teacher Effectiveness Inventory (NCTEI).

Hasil: Terdapat hubungan karakteristik pembimbing klinik dan nilai keterampilan klinik asuhan kehamilan pada mahasiswa yaitu hubungan interpersonal $(\mathrm{p}=0,043)$ dan karakteristik kepribadian $(\mathrm{p}=0,024)$. Faktor dominan yang berhubungan adalah karakteristik kepribadian ( $P O R=4,4$; IK 95\%:1,02-19,08) dengan nilai $\mathrm{p}=0,048$.

Kesimpulan: Dari penelitian ini, dapat disimpulkan bahwa hubungan interpersonal dan karakteristik kepribadian pembimbing klinik dapat meningkatkan peran pembimbing klinik dalam proses pembelajaran klinik dan karakteristik kepribadian merupakan karakteristik pembimbing klinik yang paling berperan terhadap nilai keterampilan klinik asuhan kehamilan pada mahasiswa Akademi Kebidanan Sari Mulia Kota Banjarmasin.

Kata Kunci: Hubungan interpersonal, karakteristik kepribadian, kemampuan mengajar, kompetensi profesional, nilai keterampilan klinik, pembimbing klinik

\section{PRACTICE POINTS}

- Praktik klinik merupakan sarana pembelajaran yang memberikan pengalaman bagi mahasiswa untuk melakukan tindakan pelayanan secara langsung di lingkup masyarakat.

- Pembimbing klinik sangat berperan dalam proses pembentukan kompetensi mahasiswa.

- Karakteristik pembimbing klinik yang beragam akan memberikan dampak terhadap pencapaian target kompetensi mahasiswa.

- Mahasiswa harus mencapai target kompetensi yang sudah ditetapkan agar siap menjadi tenaga kesehatan yang profesional.

\section{PENDAHULUAN}

Pendidikan Diploma III Kebidanan adalah bagian dari jenjang pendidikan tinggi vokasional dengan pembagian kurikulum yaitu pembelajaran teori sebanyak $40 \%$ dan pembelajaran praktik sebanyak $60 \%$. Persentase praktik lebih banyak daripada teori, sehingga diperlukan pengelolaan pembelajaran praktik klinik yang tepat. ${ }^{1}$

Pembelajaran praktik diperoleh mahasiswa melalui pembelajaran di laboratorium dan lahan praktik klinik. Pembelajaran praktik di laboratorium merupakan proses penting untuk mempersiapkan mahasiswa dalam melaksanakan pembelajaran praktik klinik. ${ }^{1}$ Pembelajaran klinik menyiapkan mahasiswa untuk pekerjaan saat menjalani praktik sebagai bidan yang berkualitas aman bagi individu, keluarga dan masyarakat. Selain itu, memungkinkan mahasiswa untuk berpartisipasi aktif, mencari solusi untuk masalah nyata dan belajar memberikan perawatan kepada pasien sehingga menjadi praktisi yang berkompetensi. ${ }^{2}$ Praktik klinik merupakan bagian penting dalam keseluruhan proses pembelajaran pendidikan Diploma III kebidanan agar tercapainya kompetensi lulusan yang diharapkan. ${ }^{3}$

Menurut Moosavi, terdapat ada 5 faktor pada pembelajaran klinik yaitu pembimbing klinik, program pendidikan, lingkungan praktik, mahasiswa dan sistem evaluasi. ${ }^{4}$ Pembelajaran klinik dibimbing oleh pembimbing klinik yang memiliki peran penting dalam mempersiapkan mahasiswa untuk menjadi tenaga kesehatan yang kompeten di lingkungan praktik. $^{5}$

Terdapat lima aspek tentang perilaku pembimbing yang penting untuk pembelajaran yang efektif yaitu 
bersikap jujur dengan siswa, motivasi untuk mengajar, kemauan untuk mendengarkan dan menggunakan keterampilan komunikasi yang baik, mengawasi siswa secara efektif dan menjadi teladan yang positif. Karakteristik ini dapat dipertimbangkan ketika menentukan pembimbing klinik berikutnya dan saat merencanakan program pendidikan dalam layanan untuk pembimbing klinik untuk mempromosikan pembelajaran mahasiswa. ${ }^{2}$ Berdasarkan beberapa hasil penelitian pembimbing klinik yang efektif yang adalah pembimbing yang memiliki kompetensi profesional, hubungan interpersonal, karakteristik kepribadian dan kemampuan mengajar dalam proses memberikan bimbingan..$^{6.8}$

Menurut Puter, manajemen pembelajaran klinik kebidanan pada mahasiswa kebidanan di Banjarmasin yaitu penilaian masih bersifat subjektif dan hasil yang diperoleh mahasiswa relatif sama. ${ }^{9}$ Berdasarkan hal tersebut, peneliti ingin mengetahui hubungan karakteristik pembimbing klinik yang dikaitkan dengan nilai keterampilan klinik asuhan kehamilan pada mahasiswa Akademi Kebidanan Sari Mulia Kota Banjarmasin. Tujuan dalam penelitian ini adalah untuk menganalisis hubungan karakteristik pembimbing klinik dan nilai keterampilan klinik asuhan kehamilan serta menganalisis karakteristik pembimbing klinik yang paling berperan terhadap nilai keterampilan klinik asuhan kehamilan pada mahasiswa Akademi Kebidanan Sari Mulia Kota Banjarmasin.

\section{METODE}

Jenis penelitian ini menggunakan metode kuantitatif dengan rancangan penelitian observasional analitik dengan pendekatan potong lintang. Penelitian dilaksanakan pada bulan Januari-Februari 2019 saat mahasiswa melakukan praktik klinik kebidanan I di Puskesmas wilayah Kota Banjarmasin. Responden dipilih secara total sampling, yakni mahasiswa pada semester III. Pemilihan mahasiswa semester III adalah untuk mendapatkan respon yang lengkap dari mahasiswa karena ini merupakan praktik klinik yang pertama dialami mahasiswa mengenai asuhan kebidanan. Sampel penelitian ini adalah mahasiswa semester III Akademi Kebidanan Sari Mulia Kota Banjarmasin berjumlah 25 mahasiswa yang sedang praktik dan 11 pembimbing klinik di 11 Puskesmas wilayah Kota Banjarmasin yang memenuhi syarat inklusi.

Kriteria inklusi mahasiswa adalah semester III Akademi Kebidanan Sari Mulia Kota Banjarmasin yang sedang melaksanakan pembelajaran praktik klinik kebidanan I di Puskesmas dan telah lulus ujian teori dan laboratorium untuk asuhan kehamilan. Kriteria eksklusi mahasiswa adalah yang tidak hadir atau sakit pada saat penelitian berlangsung dan yang mengulang pembelajaran praktik klinik kebidanan I. Sedangkan kriteria inklusi pembimbing klinik adalah memiliki sertifikat clinical instructor, minimal Diploma IV, pengalaman klinik minimal 5 tahun dan berinteraksi langsung dengan mahasiswa. Kriteria eksklusi pembimbing klinik adalah yang tidak hadir atau sakit pada saat penelitian berlangsung.

Variabel penelitian ini terdiri dari dua variabel, yaitu variabel dependen dan independen. Pada penelitian ini, karakteristik pembimbing klinik adalah variabel independen. Sedangkan nilai keterampilan klinik asuhan kehamilan merupakan variabel dependen. Pengambilan data primer menggunakan kuesioner Nursing Clinical Teacher Effectiveness Inventory (NCTEI). Instrumen NCTEI yang digunakan bertujuan untuk menilai karakteristik pembimbing klinik menurut mahasiswa yang dibimbing secara langsung oleh pembimbing klinik tersebut. Instrumen terdiri dari empat kelompok karakteristik pembimbing klinik yaitu kompetensi profesional, hubungan interpersonal, karakteristik kepribadian dan kemampuan mengajar. Setelah dilakukan uji validitas, kuesioner ini terdiri dari 33 pernyataan dengan $r$ hitung lebih besar dari $r$ tabel yaitu $r$ $>0,468 \quad(n=18)$. Reliabilitas dengan Cronbach's Alpha didapatkan hasil $\mathrm{r}$ alpha $>\mathrm{r}$ tabel. Hal ini membuktikan 33 item pernyataan kuesioner ini reliabel.

Analisis data statistik pada penelitian ini menggunakan software SPSS. Pada penelitian ini akan di uji menggunakan uji independent samples t-test, Mann Whitney, dan analisis regresi logistik.

Penelitian ini telah mendapatkan persetujuan dari Komisi Etik Fakultas Kedokteran Universitas Padjadjaran Bandung nomor 1419/UN6.KEP/ EC/2018. 


\section{HASIL DAN PEMBAHASAN}

Data yang dianalisis dalam penelitian ini yaitu pada responden pembimbing klinik meliputi karakteristik dasar yang terdiri dari umur dan masa kerja, sedangkan karakteristik pembimbing klinik yang menjadi variabel bebas yaitu kompetensi profesional, hubungan interpersonal, karakteristik kepribadian dan kemampuan mengajar. Pada responden mahasiswa yang akan di analisis mengenai indeks prestasi (IP) semester II yang menjadi variabel terikat.

Tabel 1. Karakteristik dasar subjek penelitian

\begin{tabular}{clc} 
No & Karakteristik subjek & Jumlah \\
\hline 1 & Pembimbing klinik (n=11) & \\
& Umur (tahun) & \\
& $\bar{x}$ (SD) & $47,7(6,3)$ \\
& Rentang & $32-54$ \\
& Masa kerja (tahun) & $12,4(2,8)$ \\
& $\bar{x}$ (SD) & $5-15$ \\
& Rentang & \\
\hline 2 & Mahasiswa (n=25) & \\
& IP Semester II & $3,29(0,08)$ \\
& $\bar{x}$ (SD) & $3,05-3,41$ \\
& Rentang &
\end{tabular}

Berdasarkan data pada tabel 1, didapatkan hasil dari 11 responden pembimbing klinik yang memiliki rata-rata umur 47 tahun dengan rentang masa kerja adalah 5-15 tahun. Pada 25 responden mahasiswa didapatkan rata-rata indeks prestasi (IP) semester II adalah 3.29 .

Tabel 2. Distribusi frekuensi nilai keterampilan klinik asuhan kehamilan

\begin{tabular}{cccc} 
No & $\begin{array}{c}\text { Nilai } \\
\text { keterampilan } \\
\text { klinik }\end{array}$ & Jumlah & $\%$ \\
1 & 72 & 2 & 8 \\
2 & 75 & 9 & 36 \\
3 & 80 & 13 & 52 \\
4 & 97.5 & 1 & 4 \\
\hline
\end{tabular}

Tabel 2 menyajikan hasil distribusi frekuensi nilai keterampilan klinik yang paling banyak diberikan oleh pembimbing klinik kepada mahasiswa kebidanan yaitu sebesar $52 \%$ pada nilai 80 .

Tabel 3. Perbandingan skor karakteristik pembimbing klinik dan nilai keterampilan klinik asuhan kehamilan

\begin{tabular}{|c|c|c|c|c|}
\hline \multirow[t]{2}{*}{ No } & \multirow{2}{*}{ Karakteristik } & \multicolumn{2}{|c|}{$\begin{array}{c}\text { Nilai keterampilan klinik asuhan } \\
\text { kehamilan }\end{array}$} & \multirow[t]{2}{*}{ Nilai $p^{*}$} \\
\hline & & $<80(n=11)$ & $\geq 80(n=14)$ & \\
\hline 1 & $\begin{array}{l}\text { Kompetensi profesional } \\
\bar{x}(\mathrm{SD}) \\
\text { Rentang }\end{array}$ & $\begin{array}{l}46,1(8,7) \\
33,3-66,7\end{array}$ & $\begin{array}{c}53,9(11,0) \\
40,7-74,0\end{array}$ & $0,066^{*}$ \\
\hline 2 & $\begin{array}{l}\text { Hubungan interpersonal } \\
\quad \bar{x}(\mathrm{SD}) \\
\text { Rentang }\end{array}$ & $\begin{array}{l}47,2(12,5) \\
33,3-66,7\end{array}$ & $\begin{array}{l}56,1(8,4) \\
42,9-66,7\end{array}$ & $0,043^{*}$ \\
\hline 3 & $\begin{array}{l}\text { Karakteristik kepribadian } \\
\text { Median (SD) } \\
\text { Rentang }\end{array}$ & $\begin{array}{l}47,6(12,8) \\
33,3-66,7\end{array}$ & $\begin{array}{c}64,3(10,7) \\
33,3-71,4\end{array}$ & $0,024^{* *}$ \\
\hline 4 & $\begin{array}{l}\text { Kemampuan mengajar } \\
\bar{x}(\mathrm{SD}) \\
\text { Rentang }\end{array}$ & $\begin{array}{l}46,7(9,8) \\
33,3-66,7\end{array}$ & $\begin{array}{c}55,2(11,7) \\
33,3-70,0\end{array}$ & $0,064^{*}$ \\
\hline
\end{tabular}

Keterangan *) berdasarkan Uji T-Test; **) Uji Mann-Whitney 
Tabel 3 menyajikan hasil yang didapatkan bahwa nilai keterampilan klinik memiliki hubungan yang bermakna pada karakteristik pembimbing klinik yaitu hubungan interpersonal dan karakteristik kepribadian dengan nilai $\mathrm{p}<0,05$.

Tabel 4. Analisis karakteristik pembimbing klinik yang paling berperan terhadap nilai keterampilan klinik pada asuhan kehamilan berdasarkan uji regresi logistik

\begin{tabular}{|c|c|c|c|c|}
\hline Karakteristik & Koefisien $\square$ & SE $\square$ & Nilai $\mathrm{p}$ & POR (IK95\%) adj. \\
\hline \multicolumn{5}{|l|}{ Model awal: } \\
\hline Kompetensi profesional & 2,485 & 1,633 & 0,128 & $12,00(0,49-294)$ \\
\hline Hubungan interpersonal & $-22,210$ & 24501 & 0,999 & $0,00(0)$ \\
\hline Karakteristik kepribadian & 23,126 & 24501 & 0,999 & $1 \mathrm{E}+01(0)$ \\
\hline Kemampuan mengajar & $-1,099$ & 1,528 & 0,472 & $0,33(0,02-6,65)$ \\
\hline \multicolumn{5}{|l|}{ Model akhir: } \\
\hline Karakteristik kepribadian & 1,482 & 0,889 & 0,048 & $4,4(1,02-19,08)$ \\
\hline
\end{tabular}

Kompetensi profesional adalah kemampuan yang harus dimiliki dalam perencanaan dan pelaksanaan proses pembelajaran untuk mengarahkan kegiatan belajar mahasiswa hingga mencapai tujuan pembelajaran. ${ }^{10}$ Pembimbing klinik merupakan orang yang berperan secara langsung bagi mahasiswa untuk mempelajari dan menerapkan teori, mendapatkan pengalaman, mempraktekkan teknik dan mengembangkan diri. Karena pengalaman dan kemampuan pembimbing klinik akan mempengaruhi kemampuan mahasiswa selama pembelajaran klinik. Pembimbing klinik dapat menciptakan pengalaman belajar yang positif bagi mahasiswa dan memberikan umpan balik yang terus berlanjut agar mahasiswa dapat mencapai kompetensi yang ditetapkan. ${ }^{11}$ Studi yang dilakukan Hayajneh menyebutkan sikap role model seorang pendidik klinik berefek positif dan direfleksikan pada proses pembelajaran mahasiswa. ${ }^{12}$

Berdasarkan hasil analisis pada penelitian ini mengenai hubungan karakteristik pembimbing klinik dan nilai keterampilan klinik asuhan kehamilan menunjukkan bahwa tidak ada hubungan kompetensi profesional dan nilai keterampilan klinik asuhan kehamilan ditunjukkan dengan nilai $p>0,05$. Hal ini berbeda dengan teori sebelumnya yang menyatakan bahwa kompetensi profesional berhubungan dengan keterampilan klinik mahasiswa. ${ }^{12} \mathrm{Hal}$ ini disebabkan karena kompetensi profesional bukan satu-satunya faktor yang dapat meningkatkan keterampilan mahasiswa.
Kemampuan pembimbing klinik untuk berinteraksi dengan mahasiswa merupakan salah satu karakteristik pembimbing klinik yang efektif. Hubungan interpersonal merupakan suatu bentuk dukungan bagi mahasiswa dari stress yang berdampak pada pencapaian kompetensi saat di lahan praktik. Selain itu, hubungan yang terbentuk dapat meningkatkan pembelajaran mahasiswa. Ditandai dengan pembimbing yang dapat didekati, dorongan untuk saling menghormati, memberikan dukungan dan mendengarkan dengan penuh perhatian. ${ }^{13}$

Peran pembimbing klinik dalam hubungan interpersonal dengan memberikan motivasi agar tercipta semangat belajar klinik yang memberikan dampak yang baik dalam mencapai tujuan praktik klinik kebidanan. ${ }^{14}$ Apabila pembimbing mampu memotivasi mahasiswa yang dibimbing agar belajar dan bekerja dengan baik maka target kompetensi mahasiswa akan tercapai. ${ }^{15} \mathrm{Hal}$ yang sama juga ditemukan pada penelitian yang dilakukan oleh Zamanzadeh menyatakan bahwa sikap respect seorang pembimbing klinik merupakan dimensi yang paling tinggi dari perilaku seorang pendidik klinik dalam memberikan bimbingan yang diidentifikasi oleh mahasiswa $^{16}$

Berdasarkan hasil analisis pada penelitian ini mengenai hubungan karakteristik pembimbing klinik dan nilai keterampilan klinik asuhan kehamilan menunjukkan bahwa ada hubungan antara 
hubungan interpersonal dan nilai keterampilan klinik asuhan kehamilan ditunjukkan dengan nilai $\mathrm{p}<0,05$. Hal ini sejalan dengan studi yang dilakukan oleh Baker mengatakan bahwa perilaku yang paling tinggi dinilai oleh mahasiswa penting bagi seorang pendidik klinik yaitu kemampuan dalam hubungan interpersonal. Beberapa sikap yang menurut mahasiswa perlu dimiliki oleh pembimbing yaitu rasa ketertarikan kepada mahasiswa dan dapat menjadi seorang pendengar yang baik bagi mahasiswa. ${ }^{17}$ Hasil tentang variabel hubungan interpersonal $\mathrm{di}$ atas di perkuat oleh penelitian yang di lakukan oleh Girija mengemukakan bahwa pembimbing klinik yang efektif yaitu memiliki hubungan interpersonal yang baik dengan nilai $\mathrm{p}=0,034{ }^{8}$

Kemampuan mengajar adalah suatu kemampuan untuk mengetahui kebutuhan pembelajaran, merencanakan instruksi yang berhubungan dengan karakteristik mahasiswa dan tujuan yang akan dicapai, mengawasi mahasiswa dan mengevaluasi hasil belajar. ${ }^{13}$ Tujuan dari pembelajaran yang meliputi aspek pengetahuan dan sikap sebenarnya akan terfokus pada aspek keterampilan. Peningkatan keterampilan memerlukan latihan untuk mendapatkan ketepatan dalam suatu pekerjaan. Suatu profesi dalam bidang kesehatan selain dari aspek pengetahuan dan sikap, aspek keterampilan menjadi penilaian penting. Selain itu, akan lebih aktif dalam pembelajaran dan mengeksplorasi dunia nyata sehingga meningkatkan cara berpikir kritis mahasiswa. $^{3}$

Pembelajaran yang dikelola dengan baik diharapkan dapat mengembangkan potensi mahasiswa, sehingga memiliki pengetahuan, keterampilan, sikap dan nilai-nilai yang mengakar pada individu mahasiswa. Pembelajaran dapat ditingkatkan dengan melibatkan peran pembimbing sebagai fasilitator. Fasilitator yang berkaitan dengan proses belajar mengajar, termasuk menumbuhkan motivasi belajar mahasiswa. Perilaku pembimbing dalam mengajar baik langsung maupun tidak langsung mempunyai pengaruh terhadap motivasi belajar mahasiswa baik yang positif maupun negatif. Sehingga kepribadian yang ditampilkan dosen dalam mengajar sesuai dengan harapan mahasiswa, maka mahasiswa termotivasi untuk belajar dengan baik, begitupun sebaliknya. ${ }^{18}$
Hasil penelitian ini tentang variabel kemampuan mengajar yang tidak berhubungan dengan nilai keterampilan klinik di perkuat oleh penelitian Adila pada tahun 2015 menunjukkan terdapat metode bimbingan yang masih monoton, kurangnya motivasi dan kurang dukungan dari pembimbing klinik. Pemberian reinforcement yang kurang dan masih rendahnya perhatian pembimbing dalam membedakan kemampuan mahasiswa. Pembimbingan yang dilaksanakan masih terkesan seadanya. Pembimbing menilai kemampuan mahasiswa juga tidak berdasarkan kualitas. Dukungan yang diberikan oleh pembimbing dalam memberikan persiapan laboratorium dan pemberian umpan balik sebelum praktik di lahan masih dianggap monoton dan belum cukup oleh mahasiswa. Belum tercipta iklim belajar yang kondusif untuk perkembangan kemampuan, ketrampilan dan sikap mahasiswa. Praktik yang dilaksanakan masih berfokus pada rutinitas dan berorientasi pada perintah. ${ }^{19}$

Berdasarkan hasil analisis pada penelitian ini menunjukkan bahwa tidak ada hubungan antara kemampuan mengajar dan nilai keterampilan klinik asuhan kehamilan ditunjukkan dengan nilai $p>0,05$. Hal ini sejalan dengan penelitian yang dilakukan oleh Della yang menyatakan bahwa aspek kemampuan mengajar memiliki nilai terendah dalam pencapaian kompetensi. ${ }^{13} \mathrm{Hal}$ ini berbeda dengan penelitian yang dilakukan oleh Parvan tahun 2016 yang mendapatkan hasil penelitian bahwa hubungan positif yang signifikan antara pembimbing keperawatan dan efektivitas pembelajaran klinik mahasiswa $(p=0,001){ }^{6}$

Karakteristik kepribadian merupakan unsur yang penting karena akan membentuk pola perilaku yang patut di contoh sebagai motivasi mendidik mahasiswa. Karakteristik kepribadian pembimbing klinik yang ramah, mendukung, penuh pengertian dan semangat akan meningkatkan pembelajaran yang diberikan. Peran pembimbing klinik tidak hanya mengajarkan mahasiswa untuk mengintegrasikan pengetahuan dan keterampilan yang terkait tetapi juga memberikan kesempatan kepada mahasiswa untuk melaksanakan peran sebagai perawat dalam memberikan asuhan keperawatan. ${ }^{20}$ Sikap yang bisa ditunjuk sebagai seorang pembimbing klinik, 
antara lain berpenampilan bersih, rapi dan gaya hidup sehat, hubungan antar pribadi dan hubungan kerja yang baik dalam tim kerjasama, menghargai, menghormati martabat dan memperlakukan pasien sebagai individu yang utuh, serta memiliki kepribadian yang dewasa dan bertanggung jawab serta memiliki dedikasi. ${ }^{21}$

Hal ini sejalan dengan hasil penelitian Alifah yang menunjukkan bahwa pembimbing klinik yang efektif yaitu pembimbing yang mendemonstrasikan kemampuan teknik dan prosedur klinis, memberikan saran-saran spesifik untuk perbaikan, menunjukkan rasa empati, mengakui kekurangan dan kelebihan yang dimiliki, dan berpikiran terbuka serta tidak menghakimi. ${ }^{22}$

Berdasarkan hasil analisis pada penelitian ini menunjukkan bahwa ada hubungan antara karakteristik kepribadian dan nilai keterampilan klinik asuhan kehamilan ditunjukkan dengan nilai $p<0,05$. Hal ini sejalan dengan penelitian yang dilakukan oleh Ismail yang mendapatkan hasil kepribadian merupakan salah satu karakteristik pembimbing klinik yang efektif dengan nilai $p<0,05$. Hasil penelitian ini tidak sesuai dengan hasil penelitian yang dilakukan oleh Rowbotham yang mengungkapkan perilaku yang tidak mencapai signifikansi statistik adalah kepribadian pembimbing dalam pengembangan mahasiswa. ${ }^{23}$

Pada mode akhir uji regresi logistikdidapatkanvariabel yang yang paling berperan terhadap nilai keterampilan klinik mahasiswa terdapat hubungan yang signifikan antara karakteristik kepribadian pembimbing klinik dan nilai keterampilan klinik asuhan kehamilan yang memiliki nilai POR $=4,4$ (IK95\%: 1,02-19,08) dan nilai $\mathrm{p}=0,048$. Hasil penelitian ini menunjukkan karakteristik kepribadian yang dibawah rata-rata memiliki risiko 4,4 kali lipat mendapatkan nilai keterampilan klinik <80. Pada penelitian ini untuk daerah Kota Banjarmasin khususnya pembimbing klinik Puskesmas menunjukkan bahwa karakteristik kepribadian paling berperan terhadap nilai keterampilan klinik mahasiswa. Hal ini sejalan dengan penelitian yang dilakukan oleh Dewanti bahwa komponen kinerja pembimbing klinik yang tertinggi adalah karakteristik kepribadian. ${ }^{11}$

\section{KESIMPULAN}

Penelitian ini menunjukkan bahwa hubungan interpersonal dan karakteristik kepribadian pembimbing klinik memiliki hubungan terhadap nilai keterampilan klinik asuhan kehamilan. Karakteristik kepribadian merupakan karakteristik yang paling berperan terhadap nilai keterampilan klinik asuhan kehamilan pada mahasiswa Akademi Kebidanan Sari Mulia Kota Banjarmasin. Sehingga pembimbing klinik harus memiliki karakteristik kepribadian yang baik terhadap mahasiswa agar proses pembelajaran klinik dapat mencapai tujuannya. Hasil penelitian ini juga menunjukkan adanya beberapa kemiripan dengan penelitianpenelitian sebelumnya dan mengkonfirmasi kembali beberapa faktor pembimbing klinik yang harus dipertimbangkan dalam program pembelajaran klinik kebidanan secara umum.

\section{SARAN}

Bagi penelitian selanjutnya, supaya menggunakan desain penelitian yang lain serta mempertimbangkan empat faktor pembelajaran klinik lainnya yaitu program pendidikan, lingkungan praktik, mahasiswa dan sistem evaluasi.

\section{UCAPAN TERIMAKASIH}

Peneliti mengucapkan terima kasih kepada Ibu Anggrita Sari, S.Si.T., M.Pd., M.Kes selaku Direktur Akademi Kebidanan Sari Mulia telah memberikan rekomendasi untuk melakukan penelitian ini dan seluruh pembimbing klinik dan mahasiswa yang terlibat selama proses penelitian.

\section{DEKLARASI KEPENTINGAN}

Para penulis mendeklarasikan bahwa tidak terdapat konflik kepentingan apapun terkait studi pada naskah ini.

\section{KONTRIBUSI PENULIS}

Ika Friscila - Mengusulkan konsep penelitian, mengerjakan detail pelaksanaan penelitian, mengolah analisis statistik dan menulis rancangan awal naskah. 
Achadiyani - Membaca awal naskah dan memberikan saran, mengusulkan saran tentang revisi naskah dari editor.

Endang Sutedja - Mengusulkan penggunaan kuesioner NCTEI, membaca naskah akhir dan memberikan saran.

\section{DAFTAR PUSTAKA}

1. Sabog RFV CL, David JJT. Effective characteristics of a clinical instructor as perceived by BSU student nurses. IJNS. 2015;5(1):5-19.

2. Okoronkwo IL, Onyia-Pat J-L, Agbo M-AE, Okpala PU, Ndu AC. Students' perception of effective clinical teaching and teacher behaviour. OJN. 2013;3(01):63.

3. Nurjanah S, Suwarsa O, Tarawan VM, Husin F, Wirakusumah FF, Susiarno H, et al. Peran penerapan model pembelajaran asuhan kehamilan terintegrasi terhadap motivasi dan kompetensi mahasiswa serta kepuasan pasien pada praktik klinik kebidanan. IJEMC. 2015;2(4):1-8.

4. Moosavi S, Fatemi S, Yazdanipour MA. Attitude of nursing, midwifery and operating room students about effective factors on clinical education. Procedia-Social and Behavioral Sciences. 2013;89:676-81.

5. Niederriter JE, Eyth D, Thoman J. Nursing Students' Perceptions on Characteristics of an Effective Clinical Instructor. SAGE Open Nursing. 2017;3:2377960816685571.

6. Parvan K, Hosseini FA, Bagherian S. The relationship between nursing instructors' clinical teaching behaviors and nursing students' learning in Tabriz University of Medical Sciences in 2016. Educ Health. 2018;31(1):32.

7. Sabog RFV, Caranto LC, David JJT. Effective characteristics of a clinical instructor as perceived by BSU student nurses. IJNS. 2015;5(1):5-19.

8. Madhavanprabhakaran GK, Shukri RK, Hayudini J, Narayanan SK. Undergraduate nursing students' perception of effective clinical instructor: Oman. IJNS. 2013;3(2):38-44.
9. Puter $\mathrm{MC}$, editor. Manajemen pembelajaran klinik kebidanan pada Mahasiswa Diploma III Kebidanan di Banjarmasin. Prosiding Seminar Nasional \& Internasional; 2016;1(1):244-53.

10. Kurniawati K, Sutedja E, Husin F, Hilmanto $\mathrm{D}$, Wirakusumah $\mathrm{F}$, Susanto $\mathrm{H}$, et al. Hubungan karakteristik pembimbing klinik dengan keterampilan klinik asuhan persalinan normal pada mahasiswa Program Diploma III Kebidanan. IJEMC. 2014;1(1):23-31.

11. Dewanti S. Hubungan kinerja instruktur klinik dengan pencapaian kompetensi klinik mahasiswa keperawatan di rumah sakit di medan. Universitas Sumatera Utara. 2014.

12. Hayajneh F. Role model clinical instructor as pereived by Jordanian nursing students. J Res Nurs. 2016;16(1):23-32.

13. PutriDAW.Hubungan karakteristik pembimbing klinik dengan pencapaian kompetensi klinik mahasiswa profesi ners fakultas keperawatan universitas jember.

14. Beratha O, Wirakusuma IB, Sudibya A. Hubungan karakteristik, motivasi dan dana BOK dengan kinerja petugas KIA Puskesmas di Kabupaten Gianyar.Udayana University;2013.

15. Bobaya J, Kiling MA, Laoh JM, Losu N. Hubungan Persepsi Mahasiswa Tentang Pembimbing Klinik Dengan Pencapaian Target Praktek Klinik Keperawatan Medikal Bedah Di Badan Layanan Umum Rsup Prof. Dr. Rd Kandou Manado. Juiperdo. 2015;4(1):20-31.

16. Zamanzadeh V. Nursing Students's Perception Of Instructors's Caring Behaviors in Tabriz University of Medical Sciences. J Caring Sci. 2015;4(1):55-62.

17. Baker K. Senior Nursing Students's Perception of Clinical Teacher Behavior. School of Nursing Gardner-Webb University; 2012.

18. Murhadi TMT, Murniati A. Manajemen pembelajaran dalam meningkatkan motivasi belajar mahasiswa Prodi Diploma III Kebidanan STIKES Harapan Bangsa Banda Aceh. Jurnal Serambi Ilmu. 2018;16(1):63-9. 
19. Adila W. Peran Pembimbing Praktik Klinik pada Praktik Klinik Keperawatan Diploma III Keperawatan STIKES An-nur Purwodadi: Universitas Gadjah Mada; 2012.

20. Ismail LM-N, Aboushady RM-N, Eswi A. Clinical instructor's behavior: Nursing student's perception toward effective clinical instructor's characteristics. JNEP. 2015;6(2):96.

21. Gharbelasari DAA, Ardani MH. Hubungan pemberian motivasi eksternal dari pembimbing klinik dengan capaian target kompetensi praktik klinik keperawatan anak pada mahasiswa 2012 Di PSIK FK Undip (Skripsi): Diponegero University; 2016.

22. Alifah M, Rochana N. Hubungan Persepsi Mahasiswa Mengenai Pembimbing Klinik Terhadap Pencapaian Kompetensi Klinik Mahasiswa Keperawatan: Diponegoro University; 2017.

23. Rowbotham M, Owen RM. The effect of clinical nursing instructors on student self-efficacy. Nurse education in practice. 2015;15(6):561-6. 